\title{
Kel e a expressão de definitude em caboverdiano
}

\section{Kel and definiteness on Cape Verdean}

\author{
Wânia Miranda \\ Universidade de São Paulo (USP), São Paulo, São Paulo, Brasil. \\ miranda.wania@gmail.com
}

Resumo: O uso de kel em caboverdiano causa, por vezes, controvérsia entre os estudiosos da língua no que diz respeito à função que desempenha dentro do sintagma nominal. Alguns estudos sobre o sintagma nominal do caboverdiano apresentam kel e sua forma plural kes como possíveis artigos definidos ou afirmam que eles exercem, por vezes, o papel de artigos definidos na língua (BAPTISTA, 1997, 2002, 2007; ALEXANDRE \& SOARES 2004; entre outros). Os autores que se debruçaram sobre o tema, contudo, parecem não precisar o que licencia tal uso. Neste artigo, realizaremos uma análise dessa partícula dentro de uma perspectiva semântica, a fim de tentar esclarecer o comportamento de kel no do sintagma nominal da língua.

Palavras-chave: caboverdiano, definitude, Semântica.

\begin{abstract}
There are controversies in studies about the noun phrase in Cape Verdean specially concerning the particle kel. Some analyses present the particle kel and its plural counterpart kes as a definite article others claim this particle can assume the role of a definite article (BAPTISTA, 1997, 2002, 2007; ALEXANDRE, 2004 \& SOARES; and others). Scholars who assumed kel as a definite article,
\end{abstract}


however, did not explain what allows its use as definite article. In this paper, I will present an analysis of this particle adopting a semantic perspective in order to clarify how the particle kel functions within the noun phrase of the Cape Verdean.

Keywords: Cape Verdean, definiteness, Semantics.

Recebido em 03 de junho de 2014. Aprovado em 04 de dezembro de 2014.

\section{Introdução}

Estudos sobre o sintagma nominal do caboverdiano ${ }^{1}$ apontam $\mathrm{kel}$ e sua forma plural kes como possíveis artigos definidos, outros, por sua vez, afirmam que, embora não classificados como artigos, podem exercer esse papel na língua (ver BAPTISTA, 1997, 2002, 2007; ALEXANDRE \& SOARES, 2004; entre outros). Não há, porém, entre os estudiosos do tema, consenso sobre o que licencia tal uso.

Importante observar que tanto a classe do artigo definido quanto a dos demonstrativos podem expressar definitude. Para C. Lyons (1999), nas línguas em que não há o artigo definido, a definitude seria expressa, em alguns casos, por um demonstrativo. Esse fato poderia levar, em nossa opinião, alguns autores a afirmar que kel exerce o papel de artigo definido em caboverdiano.

Igualmente, em alguns estudos sobre o sintagma nominal do caboverdiano, parece haver um equívoco quanto à distinção entre as noções de informação dada e familiaridade ou identificabilidade, o que acaba levando a análises e interpretações dúbias sobre o comportamento de kel.

No presente artigo, empreenderemos uma discussão teórica sobre definitude, dado que tanto o artigo definido quanto o demonstrativo expressam essa noção e apresentaremos o comportamento de kel

\footnotetext{
${ }^{1} \mathrm{O}$ caboverdiano é falado nas ilhas de Cabo Verde, localizadas na costa ocidental do continente africano. Embora a língua oficial do país seja a língua portuguesa, esta é restrita à sala de aula, cerimônias oficiais e alguns meios de comunicação, sendo a língua caboverdiana amplamente utilizada no país.
} 
dentro do sintagma nominal do caboverdiano, ${ }^{2}$ a fim de entender seu comportamento na língua.

\section{A definitude segundo C. Lyons (1999)}

Ao explorar a questão da definitude, C. Lyons (1999) observa o fato de existirem, em algumas línguas, elementos que parecem ter o papel exclusivo de indicar a definitude ou indefinitude do sintagma nominal. ${ }^{3}$

O autor explora a noção de familiaridade e identificabilidade. Segundo ele, no sintagma nominal indefinido, somente o falante parece estar ciente do que é referido, enquanto que, no definido, essa consciência é compartilhada pelos interlocutores. Nesse sentido, o artigo definido assinalaria que a entidade é "familiar", enquanto o indefinido seria usado quando o falante não tivesse a intenção de compartilhar essa familiaridade.

C. Lyons argumenta, contudo, que a noção de familiaridade é um tanto problemática para a distinção definido-indefinido. Exemplos disso seriam os usos associativos, situacionais, entre outros.

$\mathrm{O}$ autor argumenta ainda que alguns linguistas preferem ver a definitude relacionada à identificabilidade. ${ }^{4} \mathrm{O}$ artigo, ele mesmo, não identifica o referente, pois se trata de uma palavra gramatical, sem conteúdo lexical descritivo. $\mathrm{O}$ máximo que pode fazer é convidar o ouvinte a explorar pistas no contexto linguístico ou extralinguístico. $\mathrm{O}$ artigo pode estar relacionado à identificabilidade, mas não à identificação. Essa hipótese, porém, não exclui a familiaridade, pois é ela que habilita o ouvinte a identificar o referente.

${ }^{2}$ Nos estudos sobre o caboverdiano, as variedades linguísticas são divididas em Sotavento e Barlavento. As variedades de Sotavento são faladas nas ilhas mais ao sul do arquipélago, ao passo que as variedades de Barlavento são faladas mais ao norte. O presente trabalho concentra-se na variedade de Sotavento, mais especificamente a falada em Santiago, onde está localizada a capital do país, a cidade de Praia.

${ }^{3}$ Esses elementos podem possuir a forma de um item lexical, como os artigos definido e indefinido do inglês, ou de um afixo, por exemplo, em árabe, com o prefixo definido al- e o sufixo indefinido $-n$.

${ }^{4} \mathrm{~A}$ ideia seria que o uso do artigo definido direciona o ouvinte ao referente do NP, assinalando que o ouvinte estaria em condições de identificá-lo. 
Para C. Lyons (1999), a identificabilidade parece dar conta, de modo mais adequado, da definitude do que a familiaridade. Todavia, há casos em que a primeira não seria possível. Os usos associativos, em geral, são problemáticos para a identificabilidade. Funcionam porque o ouvinte está apto a associar um NP definido a alguma entidade que ele espera encontrar ou associar àquela situação determinada. ${ }^{5}$

C. Lyons (1999) acrescenta que a distinção mais fundamental a ser feita é entre as línguas que possuem artigos e as que não possuem. Segundo o autor, todas as línguas possuem demonstrativos e pronomes pessoais que são, talvez, inerentemente definidos.

A marcação de definitude simples seria, na visão do autor, uma característica areal. Uma grande concentração de línguas que marcam definitude simples encontra-se na Europa ocidental e no Mediterrâneo e em partes do mundo onde línguas dessas regiões foram transplantadas pela colonização.

Haveria ainda, segundo o autor, línguas em que o artigo definido pode ser omitido quando as condições situacionais, ou do discurso, para a definitude são aplicadas, por exemplo, o hausá.

Em hausá, o sufixo definido é usado, em geral, anafórica e associativamente. Nessa língua, o aparecimento ou omissão do artigo não pode ser completamente previsto. Esse aparecimento ou omissão, contudo, é amplamente determinado pela acessibilidade do referente. Em outras palavras, um nome nu é usado quando se julga que o referente é de fácil acesso, enquanto a marca de definido é utilizada quando um esforço maior parece ser requerido. Caso a tarefa de identificar o referente seja ainda maior, um demonstrativo é usado (JAGGER, 1985).

C. Lyons (1999) salienta que, na maioria das línguas, é possível referir-se a algo previamente mencionado utilizando um demonstrativo.

Ainda sobre os demonstrativos, o sistema em que o falante é o ponto de referência primário seria, para o autor, básico e encontrado em quase todas as línguas. As línguas variam, todavia, quanto ao princípio organizacional pautado na pessoa ou na distância do falante. Os demonstrativos são quase invariavelmente acentuados, e para C. Lyons esse seria o maior ponto de contraste com os artigos definidos.

\footnotetext{
${ }^{5}$ A noção de inclusividade também é importante. A definitude com plurais e massivos não envolve unicidade, mas inclusividade: a referência é a totalidade dos objetos ou massas no contexto.
} 
Por fim, há as oposições tópico-comentário, tema-rema, dado-novo e pressuposição-foco que figuram, proeminentemente, na organização da informação. ${ }^{6}$ Muitas dessas noções, aliás, podem ser intercambiáveis.

Uma informação dada é diferente de familiaridade ou identificabilidade. Um NP definido pode representar uma informação nova, em que o referente não tenha sido introduzido previamente, ou que não seja saliente na consciência dos participantes. Um NP indefinido, por sua vez, pode ser dado, ou seja, seu conteúdo descritivo pode ter ocorrido previamente no discurso ou ele ainda pode ser parte do conhecimento comum dos falantes. A identificabilidade que caracteriza muitos definidos geralmente é uma questão de ocorrência prévia no discurso e a familiaridade é, em geral, suficiente para prover a saliência mental necessária para algo que é dado.

C. Lyons (1999) assinala que a definitude parece, empiricamente, ser um fenômeno unificado. Duas características seriam proeminentes, mas não, nas palavras do autor, completamente adequadas: a identificabilidade, que favoreceria particularmente o uso referencial, sobretudo quando o referente é uma entidade física e localizável (visualmente) no contexto; e a inclusividade, que favoreceria os usos não referenciais.

\section{Artigo definido versus demonstrativo}

Alexiadou et al. (2007) apresentam, além da noção de artigo definido de C. Lyons (1999), ${ }^{7}$ as seguintes concepções do artigo definido:

- um subordinador que assinala o status argumental a um NP complemento (ABNEY, 1987; STOWELL, 1989, 1991; SZABOLCSI, 1994, p. 81);

- um carregador "natural" de referencialidade (LOEBEL, 1989; LONGOBARDI, 1994, 1996);

\footnotetext{
${ }^{6} \mathrm{Na}$ teoria pragmática, definitude tem seu lugar na área denominada "estrutura do discurso" ou "estrutura da informação", ou ainda "estrutura temática". Essa área preocupa-se com os modos em que sentenças agrupam a mensagem transmitida, de forma a expressar o relacionamento entre a mensagem e o contexto, ou o background. ${ }^{7}$ C. Lyons (1999) concebe o artigo definido como uma categoria gramatical que, em algumas línguas, gramaticaliza a noção semântico-pragmática de definitude, apesar de a própria definitude ser considerada pelo autor como categoria gramatical.
} 
- um morfema puramente gramatical cujo papel primário é assinalar caso ao NP complemento (GIUSTI, 1993, 1997, 2002).

Sobre os demonstrativos, Alexiadou et al. (2007, p. 95) argumentam que a diferença entre eles e o artigo definido é que os primeiros são uma categoria universal, isto é, diferentemente do artigo definido, os demonstrativos são encontrados em todas as línguas. As autoras destacam ainda que os demonstrativos admitem uso duplo: são usados ou intransitivamente, sem um NP complemento, por exemplo, no inglês "this" e no alemão "diese", ou transitivamente, com um NP complemento, como o inglês "this book" e o alemão "dieses Buch". Esse último, em geral, é referido como o uso adjetival dos demonstrativos.

As duas classes expressam definitude, porém, há algumas peculiaridades que as distinguem entre si. Alexiadou et al. (2007, p. 98) assinalam que, embora ambos sejam definidos, somente o artigo definido pode referir-se a termos de classe:

(1a) O dodô está extinto.

(1b) \# Este dodô está extinto.

Além disso, de acordo com as autoras, os demonstrativos não trazem leitura genérica, denotam entidades sem descrevê-las, além de serem diretamente referenciais. $\mathrm{O}$ uso do demonstrativo envolve um contraste entre referentes.

Se, por um lado, o artigo definido e os demonstrativos compartilham os componentes semânticos da identificabilidade e da referencialidade, por outro, o elemento dêitico os coloca em conjuntos diferentes.

O componente dêitico dos demonstrativos ajuda a localizar o referente em algum ponto no contexto não linguístico. A característica dêitica é, em geral, interpretada de dois modos: ou codificam a oposição [+/ -- proximal], com o falante como ponto direto de ancoragem; ou, alternativamente, a característica dêitica é feita contingentemente na categoria gramatical de pessoa e denota associação ou proximidade do falante, ou ainda um conjunto de indivíduos que inclui o falante (ALEXIADOU et al., 2007, p. 100).

Na visão de Roberts (2002), a característica diferenciadora dos demonstrativos seria a pressuposição de uma demonstração que os 
acompanha. A autora considera os demonstrativos um tipo de NP definido, assim como os pronomes e as descrições definidas.

A autora observa ainda que os demonstrativos podem ser utilizados para fazer referência a constituintes de um discurso; podem ainda ser acompanhados por demonstração, mas também podem ocorrer sem a indicação gestual do referente e, nesse caso, na maioria das vezes, possuem um antecedente. Alguns demonstrativos podem ter a interpretação de variável presa, além de poderem ter escopo restrito sobre modais ou outros operadores. Em síntese, para Roberts (2002), os NPs demonstrativos apresentam uma gama de comportamentos que são típicos de descrições definidas e pronomes.

\section{Comportamento de kel no caboverdiano}

Quanto às argumentações sobre a existência de determinante definido em caboverdiano, Alexandre e Soares (2004) afirmam que a língua possui um artigo definido em desenvolvimento, no caso, kel. Veiga (2002, p. 67) argumenta que o artigo definido, como classe gramatical, não existe em caboverdiano. Assinala também que o emprego de kel como artigo definido é muito raro. Quint (2000) declara que essa partícula possui amplitude semântica tão vasta que, por vezes, pode cobrir a função do artigo românico ou português. Para Brüser et al. (2001), contudo, em caboverdiano, não há artigo definido.

É importante, além disso, observar que a maioria dos autores afirma não poder o uso dessa partícula ser considerado sistemático, tampouco previsível, nem na função de artigo definido nem na de demonstrativo.

O WALS (World Atlas of Language Structures Online) aponta 69 línguas ao redor do mundo que se utilizam do demonstrativo para veicular definitude. Entre elas citamos o ewe, o akan, o musgu e o xhosa no continente africano; o newar, o lahu, o tibetano e o tamang no continente asiático; o indonésio, o ma'anyan e o bajau na Indonésia; e o chashibo e o uraruna no Peru.

Neste trabalho, conjecturamos que, em caboverdiano, assim como em um número de outras línguas do mundo, o emprego do demonstrativo - nesse caso, $k e l$-tem por função também veicular definitude, embora esse uso não seja considerado frequente na língua.

Desde já, frisamos que não encontramos, pelo menos nos registros do WALS, qualquer língua que possua como único artigo o indefinido 
e que, ao mesmo tempo, empregue o demonstrativo para veicular definitude.

\subsection{Análises de $k e l$}

Baptista (2007, p. 69) advoga que kel é demonstrativo quando não há menção prévia do referente, mas um determinante anafórico quando há menção prévia. Ressaltamos, porém, que os demonstrativos também podem retomar um referente (conforme ROBERTS, 2002; LYONS, 1999). Por conseguinte, esse não poderia ser um argumento suficiente para conjecturar que kel desempenha o papel de artigo definido em caboverdiano.

Nomes modificados por kel, do mesmo modo que os nomes modificados por un (determinante indefinido da língua), podem ser interpretados como específicos ou não específicos e parecem ocorrer, segundo Baptista (2007, p. 69), em variação livre com a marca Ø.

A respeito das características de kel, observamos que:

- $\quad$ ele pode ocorrer tanto com nomes específicos quanto com não específicos;

- pode funcionar como anafórico correferencial, embora o referente possa também ser retomado na ausência de qualquer determinante;

- a menos que seja sucedido pelo pronome ki em orações relativas restritivas, não pode, sozinho, realizar anáfora por ligação;

- parece não poder ser utilizado para apresentar informações novas.

Note-se que o fato de kel poder ocorrer com nomes não específicos e não ter leitura genérica já poderia distanciá-lo da classe dos artigos definidos.

Apesar de kel, realmente, parecer expressar definitude no caboverdiano, sua presença, assim como a presença de qualquer outro determinante, não é necessária para que os nomes em caboverdiano sejam definidos (para mais detalhes sobre essa análise, ver MIRANDA (2013)). À semelhança do kriyol da Guiné-Bissau, em caboverdiano, especificadores vazios são frequentemente encontrados onde artigos definidos são previstos para o português. 
Lucchesi (1994) advoga que, em caboverdiano, não há nenhum dispositivo especial para marcar a distinção entre específico e não específico. Afirma também que o uso da partícula tida como artigo definido (kel) junto aos NPs específicos pressupostos é bastante irregular. $\mathrm{Na}$ visão do autor, o uso dessa partícula seria determinado, então, mais por fatores discursivos ou estilísticos do que por alguma necessidade de se marcar determinada referencialidade do nome. Ele destaca ainda que, além de o uso de $\mathrm{kel} \mathrm{ser} \mathrm{irregular,} \mathrm{a} \mathrm{partícula} \mathrm{também} \mathrm{pode} \mathrm{ocorrer} \mathrm{com}$ nomes não específicos, como se vê em (2): ${ }^{8}$

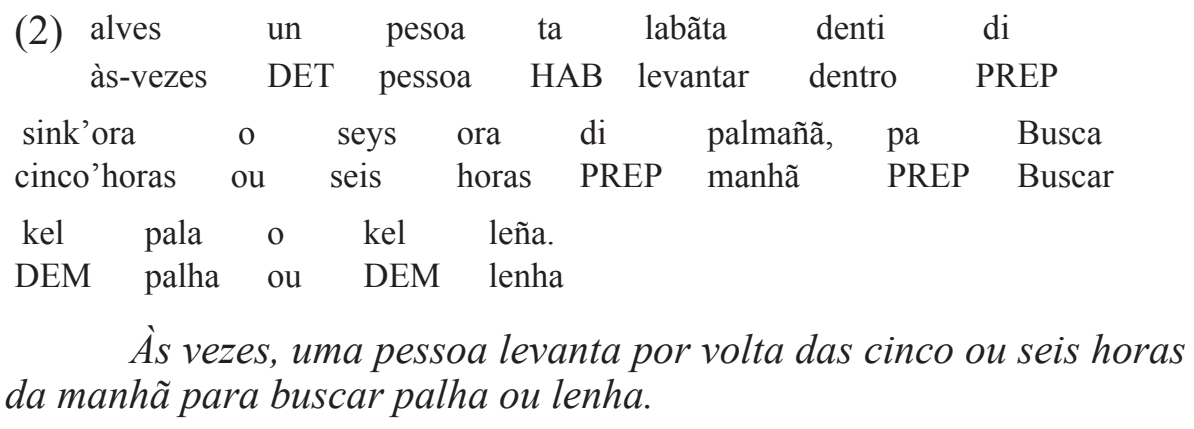

(LUCCHESI, 1994).

Em sua tese de doutorado, Baptista (1997, p. 15) aponta kel como demonstrativo usado para marcar definitude quando se refere a entidades já conhecidas. Observa, porém, que há situações em que serve puramente como marcador de definitude, explicitando, na visão da autora, uma perda da função demonstrativa.

Já em Baptista (2002, p. 24), a autora assinala que a função primária de kel seria a de um demonstrativo, embora, de acordo com

\footnotetext{
${ }^{8}$ Abreviaturas: $1 \mathrm{SG} / 2 \mathrm{SG} / 3 \mathrm{SG}: 1^{\mathrm{a}} / 2^{\mathrm{a}} / 3^{\mathrm{a}}$ pessoa do singular; $1 \mathrm{PL} / 2 \mathrm{PL} / 3 \mathrm{PL}: 1^{\mathrm{a}} / 2^{\mathrm{a}} /$ $3^{\text {a }}$ pessoa do plural; ADV: advérbio; COMP: complementizador; CONJ: conjunção; DEM: demonstrativo; DET: determinante; F: feminino; GRAU: flexão de grau; HAB: aspecto habitual; IMPF: imperfeito; Int: intensificador; M: masculino; NEG: partícula de negação; OBJ: objeto; OBL: oblíquo; PFV: perfectivo; PON: aspecto pontual; POSS: possessivo; POT: aspecto potencial; PREP: preposição; PROG: aspecto progressivo; PST: passado; PRON: pronome; QP: sintagma quantificador; REFL: reflexivo; T: pronome tônico.
} 
ela, possa desempenhar o papel de determinante definido na língua. Para defender a dupla função de kel em caboverdiano, Baptista argumenta que a língua tem seguido o caminho evolutivo comum aos determinantes em várias línguas no mundo, em que artigos definidos são desenvolvidos de demonstrativos. ${ }^{9}$

Segundo a autora, por regra, o caboverdiano não marca um NP como definido por meio de determinante aberto. O uso de kel como determinante definido seria para referir-se a uma entidade conhecida no discurso, mas não necessariamente que já tenha sido introduzida previamente.

$\mathrm{Na}$ seção 2, vimos que o demonstrativo, além de retomar um referente, pode ser utilizado para referir-se a uma entidade familiar no discurso, mesmo sem essa entidade ter sido introduzida anteriormente. Essa não seria uma função exclusiva do artigo definido.

Em algumas línguas em que o demonstrativo pode ser usado como artigo definido, quando cumpre a função de artigo definido, em geral, ocorre em posição diferente dentro do sintagma nominal. Em swahili, por exemplo, o demonstrativo segue o nome quando usado demonstrativamente, mas o precede quando usado como artigo definido. A situação inversa é atestada em ute, shambala e pa'a (LYONS, 1999).

Diferentemente do que apontamos em Miranda et al. (2010), kel pode introduzir um referente no discurso, mas isso não significa que seja uma entidade desconhecida dos interlocutores. É importante sublinhar aqui a distinção entre informação dada e nova versus familiaridade e identificabilidade, realizada por C. Lyons (1999) e apresentada aqui na seção 2 .

Caso a entidade faça parte do conhecimento partilhado entre os interlocutores, ela pode ser introduzida no discurso por kel. Nesse caso, o que está em jogo é a familiaridade, que, de acordo com C. Lyons (1999), é suficiente para prover a saliência mental necessária a algo que é dado. Em suma, "informação dada" não significa obrigatoriamente que tenha sido previamente introduzida no discurso.

Nos dados (3) e (4), temos a presença de kel com um NP em sua primeira ocorrência no discurso: ${ }^{10}$

\footnotetext{
${ }^{9}$ Salientamos, porém, que explicações diacrônicas podem não ser as mais adequadas em análises que apresentam recorte sincrônico, como é o caso do estudo da autora em questão.

${ }^{10}$ Os dados da presente pesquisa foram coletados em trabalho de campo realizado no mês de julho do ano de 2012, na ilha de Santiago, em Cabo Verde.
} 
(3) Inton, ten kel fésta, primeru Festa Ki Então, ter DEM festa, primeiro Festa PRON.CONJ.PREP

$\begin{array}{llll}\text { nu } & \text { ta } & \text { ten } & \text { li } \\ 1 \mathrm{PL} & \mathrm{HAB} & \text { ter } & \mathrm{ADV}\end{array}$

Então, tem aquela festa, a primeira festa que nós temos aqui ...

(RODRIGUES, 2007).

$\begin{array}{llllllllll}\text { (4) Kel otu } & \text { dia } & \text { dimingu, } & \text { Ta } & \text { Ledu } & \text { na } & \text { kel } & \text { otu } & \text { kasa. } \\ \text { DEM } & \text { outro } & \text { dia } & \text { domingo } & \text { HAB } & \text { ler.PST } & \text { PREP } & \text { DET } & \text { outro } & \text { Casa }\end{array}$

Naquele domingo, [nós] líamos naquela outra casa.

(BAPTISTA, 2002, p. 28).

Em (5), o referente também é introduzido no discurso por kel. O referente, no entanto, torna-se familiar através da explicação que se segue: não é qualquer mulher, é a mulher que mora próximo, ao lado. Em outras palavras, o referente faz parte do common ground. ${ }^{11}$

$\begin{array}{llllllll}\text { "N } & \text { ta } & \text { bai } & \text { ku } & \text { bo", } & \text { kel } & \text { mudjer } & \text { Ki } \\ \text { 1SG } & \text { HAB } & \text { Ir } & \text { PREP } & \text { 2SG } & \text { DEM } & \text { mulher } & \text { PRON.CONJ.PREP }\end{array}$

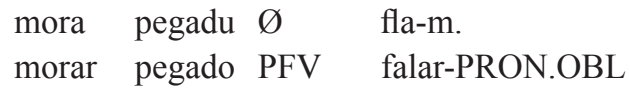

"Eu vou com você", disse aquela mulher que mora ao lado.

Outro argumento utilizado para defender o status de kel como artigo definido é a sua aparente impossibilidade de ocorrer juntamente com possessivos (ALEXANDRE; SOARES, 2004).

Alexandre e Soares (2004) afirmam que kel é um artigo definido que está em desenvolvimento no caboverdiano. Um dos testes em favor dessa hipótese seria a presença de possessivos. Segundo os autores, quando um possessivo está presente, kel / kes não poderiam ocorrer sem o clítico demonstrativo.

${ }^{11}$ Conhecimento compartilhado entre os interlocutores. 
A sentença (6) é utilizada pelos autores como controle, para exemplificar que o pronome possessivo pode ocorrer sem $\mathrm{kel} / \mathrm{kes}$.

(6) $\mathrm{N} \quad \varnothing$ atxa rabes pamodi e $\mathrm{ka} \quad \varnothing \quad$ kumi

1SG PFV achar estranho porque 3SG NEG PFV comer

$$
\begin{array}{ll}
\text { nha } & \text { kumida. } \\
\text { 1SG.POSS } & \text { comida. }
\end{array}
$$

Achei estranho porque ele não comeu minha comida.

(ALEXANDRE; SOARES, 2004, p. 340).

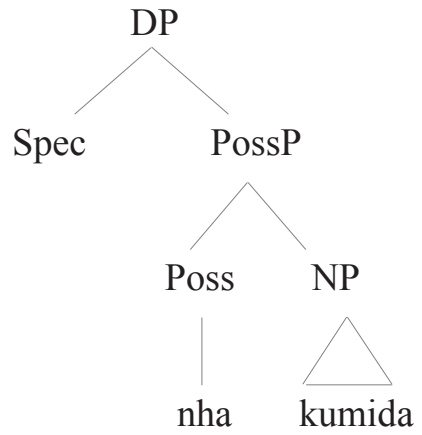

A sentença (7), por sua vez, é considerada agramatical, pois kel / kes não poderiam, segundo a proposta dos autores, ocorrer com o pronome possessivo sem a presença do clítico ( $l a$ ou $l i$ ) posposto ao nome. Já a sentença (8), com kel / kes com o pronome possessivo e somado ao clítico, é considerada gramatical. Representamos o NP a seguir.
*Dja bu
odja kes nha
fidju femia?
ADV 2SG.POSS olhar DEM 1SG.POSS Filho fêmea

(ALEXANDRE; SOARES, 2004, exemplo adaptado)

(8) Dja bu odja kes nha fidju femia li?

ADV 2SG.POSS olhar DEM 1SG.POSS filho fêmea ADV

Você já viu estas minhas filhas aqui?

(ALEXANDRE; SOARES, 2004, exemplo adaptado) 


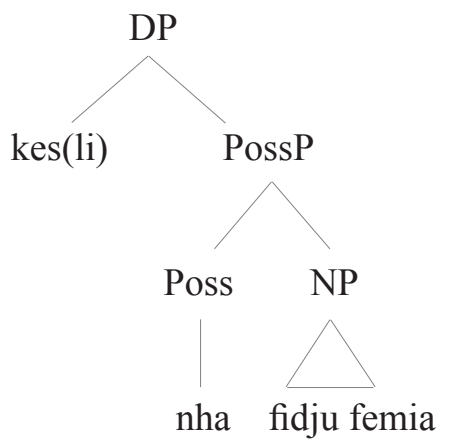

e (10):

Como contra-argumento, no entanto, apresentamos os dados (9)

(9) Kel bu amigo Ø tilifona.

DEM 2SG.POSS amigo PFV telefonar.

Aquele teu amigo telefonou.

(10) $\mathrm{Bu}$ nem $\mathrm{Ka} \varnothing$ dêxa-m kel bu livru. 2SG.POSS NEG NEG PFV deixar-1SG.OBJ DEM 2SG.POSS livro.

Você nem deixou aquele seu livro para mim.

(QUINT, 2000, p. 183).

Em Miranda (2013a), observamos através dos dados (9) e (10) que a hipótese apresentada por Alexandre e Soares (2004) sobre a alternância entre kel e os pronomes possessivos na mesma posição sintática não poderia ser sustentada e indicamos a necessidade de maior aprofundamento na análise sobre o que causa a agramaticalidade de (7). Logo, esse argumento não poderia ser utilizado para a defesa de kel como um artigo definido, dado que, conforme apresentamos acima, a coocorrência com pronomes possessivos é possível.

Igualmente, mesmo em português, língua que, atestadamente, possui artigo definido, tanto este quanto o pronome demonstrativo podem coocorrer com o pronome possessivo, como pode ser observado na representação a seguir. 


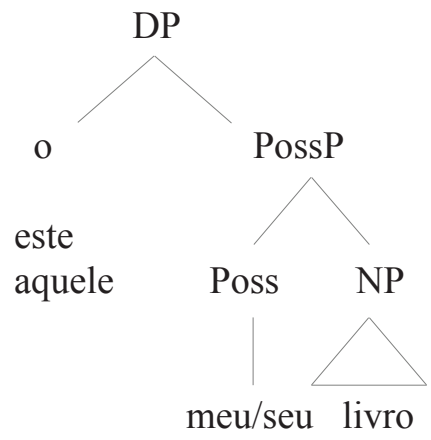

De volta às características de kel e de acordo com o que apresentamos em Miranda et al (2010), essa partícula não pode ser utilizada para expressar generalizações (ver dado em (11)). Aqui, chamamos a atenção para o argumento de Alexiadou et al. (2007) apresentado na discussão teórica sobre as classes artigo definido e demonstrativo, uma vez que as autoras apontam que o demonstrativo não admite leitura genérica.

Observamos que, mesmo com a presença da partícula aspectual de habitualidade, que poderia favorecer a leitura genérica, a presença de kel não permite tal leitura.

(11) *Tudu kel brasileru ta gosta di futibol. Todo DEM brasileiro HAB gostar PREP futebol.

e (13).

Para expressar leitura genérica, as formas adequadas seriam (12)

(12) Tudu kenha é brasileru ta gosta Di futibol.

Todo quem ser brasileiro HAB gostar PREP futebol.

Tudo que é brasileiro gosta de futebol.

(13) Tudu brasileru Ta gosta di futibol.

Todo brasileiro HAB gostar PREP futebol.

Todo brasileiro gosta de futebol. 
Kel também não pode ser utilizado para introduzir entidades desconhecidas: em um contexto no qual Maria foi assassinada brutalmente, a sentença (14) só será aceita se a pessoa que a proferir conhecer a identidade do assassino. Kel não poderia ser usado para referir-se a um assassino incógnito de Maria.

$\begin{array}{llllllll}\text { Kel } & \text { ómi } & \text { Ki } & \varnothing & \text { máta } & \text { Maria } & \text { é } & \text { dodu. } \\ \text { DEM homem } & \text { PRON.CONJ.PREP } & \text { PFV } & \text { matar } & \text { Maria } & \text { ser } & \text { doido }\end{array}$

Aquele homem que matou (a) Maria é doido.

(Miranda et al., 2010).

Em Miranda et al. (2010) apontamos que, caso o falante saiba que foi João quem matou Maria, ele pode usar a sentença (15).

(15) Djon kel Ki $\varnothing$ máta Maria.

João DEM PRON.CONJ.PREP PFV matar Maria

João, aquele que matou a Maria.

(Miranda et. al, 2010)

Se João não estiver presente na situação, o falante pode valer-se das sentenças (16) e (17):

(16) Kel dódu Ki $\varnothing$ máta Maria é Djon. DEM doido PRON.CONJ.PREP PFV matar Maria ser João Aquele doido que matou Maria é o João.

(Miranda et. al, 2010)

(17) Djon kenha Ki $\varnothing$ máta Maria. João quem PRON.CONJ.PREP PFV matar Maria O João (foi) quem matou a Maria. 
As características arroladas acima parecem corroborar a hipótese de que, em caboverdiano, não há artigo definido e que $\operatorname{kel}(s)$ se comportaria principalmente como demonstrativo.

\subsection{Kel li, Kel la}

Kel pode ainda ocorrer com os advérbios $l i$ e la, em geral, pospostos ao nome modificado pelo demonstrativo. De acordo com Brüser et al. (2001), kel nada diz sobre a proximidade ou distância do referente, se espacial ou temporal. O traço [+/ - distal (ou proximal)] do demonstrativo kel é realizado por meio dos advérbios li (ver (18) e (19)) e la (ver (20) e (21)), que indicam proximidade e distância do falante, respectivamente. ${ }^{12}$

(18) Ami Ø panha kel latona li xei d'agu.

1SG.T PFV pegar DEM lata.GRAU ADV cheia PREP'agua

Eu peguei esta latona aqui cheia d'água.

(19) Ten un punhal da'kel grandura li. ter DET punhal PREP'DEM grandeza ADV

Tem um punhal grandão assim.

(20) $\mathrm{N} \varnothing$ ben $\mathrm{Ku}$ kónpra riba $\varnothing$ sacu simentu Pergunta 1SG PFV vir PREP compra em.cima saco cimento pergunta

kel mudjer La ki é nha Kumadri

DEM mulher ADV PRON.CONJ.PREP ser 1SG.POSS Comadre

tudu alguém $\mathrm{Ki}$ nasci li é sim

todo alguém PRON.CONJ.PREP nascer ADV ser assim

Eu vim com compra em cima do saco de cimento, pergunta para aquela mulher lá, que é minha comadre, todo mundo que nasce aqui é assim.

${ }^{12}$ Para mais detalhes sobre essa argumentação, ver Miranda (2013a). 
(21) $\mathrm{N}$ ta Recebe dôs kontu, si encomendadu mais 400 1SG HAB Receber dois conto se encomendado mais 400 escudos, na lojinha ki ten lá $\mathrm{Na}$ escudos, PREP loja.GRAU PRON.CONJ.PREP tem ADV PREP

kel buati la.

DEM boate ADV

Eu recebo dois contos, se é encomendado mais quatrocentos escudos, na lojinha que tem lá naquela boate lá.

Veiga (2002, p. 70) assinala que kel li indica a proximidade de quem fala (o espaço da primeira pessoa), ao passo que kel la pode ser usado tanto para indicar a proximidade da pessoa com quem se fala (o espaço da segunda pessoa) quanto o espaço da terceira pessoa.

\subsection{Kriyol da Guiné-Bissau e o caboverdiano}

O kriyol da Guiné-Bissau e o caboverdiano compartilham diversas características. Entre elas estaria o comportamento do pronome demonstrativo.

Kihm (1994) analisa kil do kriyol como demonstrativo distal. Para o autor, na gramática do kriyol, não há nenhuma marcação explícita quanto à eventual identificabilidade da entidade.

$\mathrm{Na}$ análise de Kihm (1994), o uso de un em kriyol pode ser associado à introdução de novos referentes, como em (22), e de nomes sem determinantes, associados a referentes pressupostos, conforme (23).

(22) I yera ba un tarbaju garandi pa mi.

DET ser.PST PST DET trabalho grande PREP 1SG.OBL

Este foi um grande trabalho para mim.

(KIHM, 1994).

(23) La ja tarbaju yera menus. ADV já trabalho ser.PST menos.

Lá, o trabalho já foi menor.

(KIHM, 1994). 
Em kriyol, a função anafórica pode ser realizada pelo especificador vazio, como caso especial de especificidade, mas também é possível por meio do uso do demonstrativo distal kil, embora frequentemente seja difícil decidir se esse uso é anafórico ou dêitico.

$\begin{array}{lllll}\text { (24) Kil } & \text { asasinus } & \text { bin } & \text { di } & \text { elikóteru. } \\ \text { DEM assassinos } & \text { vir } & \text { PREP } & \text { Helicóptero }\end{array}$

Os assassinos vieram de helicóptero.

(KIHM, 1994).

Em (24), notícia transmitida em um jornal, a função de kil não pode ser, segundo as análises de Kihm (1994), mais do que indicar que os assassinos referidos são os mesmos mencionados anteriormente. Quando usado anaforicamente, kil não pode ser reforçado com la, seguido do núcleo nominal. Kil asasinus la significa "aqueles assassinos", com força dêitica. A partícula kil em kriyol é analisada como demonstrativo distal; a proximidade ou distância é medida relativamente pelo falante e pode ser material ou ideal, referir-se a espaço ou tempo, ou ainda a ambos.

Observamos que tanto a introdução de novos referentes associada a un quanto a retomada de referente por meio de nomes sem determinantes ocorrem nas duas línguas, o caboverdiano e o kriyol. Todavia, diferentemente de kil do kriyol, kel não poderia ser analisado como demonstrativo distal, sem a presença dos pronomes clíticos, uma vez que são estes que indicam a proximidade ou distância do falante.

\subsection{Kel li versus Es (li)}

No que concerne ao determinante es, Quint (2000) aponta que seria menos empregado que $\mathrm{kel}$ e essencialmente por contraste a ele, sendo utilizado apenas com nomes singulares. Quint (2009) argumenta que es seria equivalente ao demonstrativo este do português, e serviria para designar um ser ou coisa próximos no espaço ou no tempo.

Alexandre e Soares (2004) afirmam que não há dúvidas quanto ao estatuto de es como demonstrativo, mesmo quando ocorre sem o clítico-li. 
Para Brüser et al. (2001), es "situa-se sempre espacialmente próximo do locutor ou temporalmente próximo do momento da enunciação".

Observamos em nossas análises, porém, que es, apesar de ser aceito quando apresentado em alguns contextos - mas não em todos, como mostraremos a seguir -, é pouco empregado na fala corrente dos caboverdianos, embora aparente ter realmente uma função demonstrativa. Ao que parece, essa função estaria restrita mais a uma questão temporal do que à distância do falante.

$\mathrm{Na}$ sentença (25), esses dias têm de estar próximos. ${ }^{13} \mathrm{O}$ falante não sabe ao certo em que dia irá a Assomada, mas o dia tem de ser próximo - digamos, na semana corrente ou na seguinte. A sentença (25) não será adequada caso a ida a Assomada se dê em mais de uma semana. Nesse caso, será mais adequado dizer a sentença (26) e, aqui, o mês tem de ser o presente. Se a ida a Assomada se der no mês seguinte ou em outro mês distante, deve-se realizar uma referência explícita, tal como (27) ou (28).

(25) Es dia $\mathrm{Li} \mathrm{N}$ ta bai pa Somada. DEM dia ADV $1 \mathrm{SG}$ HAB ir PREP Assomada

Esses dias eu vou para Assomada.

(26) Es mês li $\mathrm{N}$ ta bai pa Somada. DEM mês ADV 1SG HAB ir PREP Assomada

Este mês (aqui) eu vou para Assomada.

(27) Mês $\mathrm{Ki}$ ben $\mathrm{N}$ ta bai pa Somada. Mês PRON.CONJ.PREP vem 1SG HAB ir PREP Assomada

No mês que vem eu vou para Assomada.

(28) Setenbru $\mathrm{N}$ ta bai pa Somada. setembro 1SG HAB Ir PREP Assomada

Em setembro eu vou para Assomada.

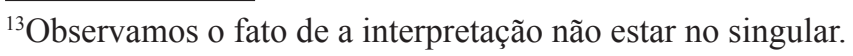


Em um contexto no qual algumas pessoas estão conversando próximas ao falante, a sentença (29) não se emprega. Nesta situação, o falante oferece a sentença (30), apontando gestualmente para as pessoas. ${ }^{14}$

(29) *Es pesoa li sta papia.

DEM pessoas ADV estar conversar

(30) Kes pesoa/(gentis) la, es Sta papia (manenti).

DEM pessoa/(pessoas) ADV 3PL Estar conversar (agora)

Aquelas pessoas lá, elas estão conversando.

No caboverdiano, es é aceito para falar de um evento que teve lugar no passado recente, como a noite anterior, por exemplo, em (31). Entretanto, de modo inesperado, o determinante es não é utilizado para referir-se a algo que ocorre no momento da fala nem para referir-se a algum objeto que esteja na posse do falante.

Em (32), o informante refere-se à música que está tocando naquele exato momento na rádio. Já em (33), a criança refere-se à caneta que está em suas mãos, pedindo-a a sua mãe. Em (34), o falante está com duas colheres, uma em cada mão, e pede para escolher entre uma das duas.

(31) Es noti txobi txuba.

DEM noite chover chuva

Esta noite choveu.

(32) Kel musica li, $\mathrm{N} \quad \mathrm{Ka}$ konxi.

DEM musica ADV 1SG NEG Conhecer

\footnotetext{
${ }^{14} \mathrm{Um}$ fato interessante é que es, referindo-se a seres animados no singular, causará estranhamento aos falantes nativos. Nesse caso, ou seja, quando nós, pesquisadores, usamos es para referir-nos a seres animados no singular, na grande maioria das vezes o falante nos "corrigirá", afirmando que es só pode ser utilizado quando houver mais de uma pessoa. Esse estranhamento pode ser causado, talvez, pelo fato de o pronome de terceira pessoa do plural ser homófono ao demonstrativo.
} 


\section{Essa música (aí) eu não conheço.}

(33) $\mathrm{N}$ kre kel li.

1SG querer DEM ADV

Eu quero esse aqui.

(34) $\mathrm{Bu}$ kre kel $\mathrm{Li} \quad \mathrm{O}$ kel li?

2SG querer DEM ADV ou DEM ADV

Você quer essa ou essa (aqui)?

Embora es seja aceito pelos falantes - exceto no caso de seres animados-, quando lhes é apresentado o contexto, esse pronome não se mostra tão produtivo na língua.

Para Veiga (2002), tanto es, es li quanto kel li indicam proximidade da pessoa que fala. Observamos que es encontra-se em expressões cristalizadas, por exemplo, "es anu" (esse ano), ou "es noti" (essa noite) e ainda em expressões de saudação, como "Es bida?" ou "Es korpu?". Contudo, ao que parece, a função de indicar proximidade do falante parece ser mais associada a kel li.

Para Baptista (1997), a diferença semântica entre kel e es é que, enquanto aquele pode indicar proximidade e distância, es estaria restrito apenas à indicação de proximidade.

É interessante observar ainda que Quint (2009) assinala -- por se tratar de uma obra de ensino da língua -- que, em caso de dúvida, deve-se utilizar sempre kel, exceto em expressões que se refiram ao momento da enunciação ou do futuro próximo.

\section{Considerações}

Neste artigo, apresentamos o comportamento de kel, kel li, kel la e es (li) dentro do sintagma nominal do caboverdiano. Apontamos que nessa língua não há artigo definido e que kel / kes, analisado com um demonstrativo, é utilizado para veicular definitude. Tal uso, todavia, não pode ser considerado frequente, uma vez que sintagmas anafóricos são retomados, em geral, sem a presença do demonstrativo. 
Apontamos ainda que os usos dêiticos estão frequentemente associados ao uso de kel li e kel la, que indicam, respectivamente, proximidade e distância do falante. O uso de es (li) para indicar proximidade, por sua vez, parece estar restrito a indicações temporais e expressões cristalizadas.

No que diz respeito às controvérsias geradas sobre o estatuto de $\mathrm{kel}$, observamos que os comportamentos tomados por alguns autores para defender seu estatuto como artigo definido são típicos dos demonstrativos, por exemplo, retomar um referente no discurso. Ademais, de acordo com C. Lyons (1999), os demonstrativos são sempre definidos.

Por fim, observamos que, conforme já mencionado, não há nos registros do World Atlas of Language Structures Online nenhuma língua que possua, ao mesmo tempo, a característica de possuir como único artigo o indefinido e ainda usar um demonstrativo como marcador de definido. No entanto, diferentemente do que consta no WALS, nossas análises apontam para, pelo menos, duas línguas que compartilham dessas duas características concomitantemente, a saber, o caboverdiano e o kriyol da Guiné-Bissau.

\section{Referências}

ABNEY, S. P. The English noun phrase in its sentential aspect. 1987. Thesis (PhD). Masschussets Institute of Technology, Cambrigde, MA, 1987.

ALEXANDRE, N.; SOARES, N. V. O domínio nominal em crioulo de Cabo Verde: o puzzle dos bare nouns. ENCONTRO NACIONAL DA ASSOCIAÇÃO PORTUGUESA DE LINGUÍSTICA APL, 20., 2004, Lisboa. Anais... Universidade de Lisboa, 2004, 2004. p. 337-350

ALEXIADOU, A.; Haegeman, L.; Stavrou, M. Noun phrase in the generative pespective. Berlim / New York: Mouton de Gruyter, 2007.

BAPTISTA, M. The morpho-Syntax of nominal and verbal categories in capeverdean creole. 1997. Thesis (PhD), Harvard University, Cambridge, MA, 1997.

. The syntax of Cape Verdean creole - the sotavento varieties, v. 54. Amsterdam / Philadelphia: John Benjamins, 2002.

On the syntax and semantics of DP in Cape Verdean creole. In: BAPTISTA, M.; GUERÓN, J. (Ed.). Noun phrases in creole language: a multi-faceted approach. Amsterdam / Philadelphia: John Benjamins 
Publishing Company, 2007. p. 61-105.

BRÜSER, M.; SANTOS, A.; DENGLER, E.; BLUM. A. Dicionário do Crioulo de Santiago (Cabo Verde): com equivalentes de tradução em alemão e português. Tübingen: Günter Narr Verlag Tubingen, 2001.

GIUSTI, G. La sintassi dei determinanti. Padova: UniPress, 1993.

GIUSTI, G. The categorial status of determiners. In: HAEGEMAN, L. (Ed.). The new comparative syntax. London: Longman, 1997. p. 95-124.

GIUSTI, G. The functional structure of noun phrases. A bare phrase structure approach. In: CINQUE, G. (Ed.). Functional structure in DP and IP: The cartography of syntactic structure, vol. 1. Oxford: Oxford University Press, 2002. p. 157-171.

JAGGER, P. J. Factors governing the morphological coding of referents in Hausa narrative discourse. 1985. Thesis (PhD) - UCLA, Los Angeles, CA, 1985.

KIHM, A. Kriyol Syntax: The portuguese-based creole language of Guinea-Bissau. Amsterdam / Philadelphia: John Benjamins Publishing Company, 1994.

LÖEBEL, E. Q as functional category. In: BHATT, E.; LÖBEL, E.; SCHMIDT, C. (Ed.) Syntactic phrase structure phenomena. Amsterdam / Philadelphia: John Benjamins, 1989. p. 133-158.

LONGOBARDI, G. Reference and proper names: A theory of n-movement in syntax and logical form. Linguistic Inquiry, v. 25(4), p. 609-665, 1994.

LONGOBARDI, G. The syntax of N-raising: a minimalist theory. Utrecht: OTS Working Papers, 1996.

LUCCHESI, D. Os artigos nos crioulos de Cabo Verde e São Tomé: princípios gerais e fatores específicos. Papia: Revista de Crioulos de Base Ibérica, vol. 3(1), p. 61-83, 1994.

LYONS, C. Definiteness. Cambridge: Cambridge University Press. 1999. MIRANDA, W., DUARTE DE OLIVEIRA M. S., QUADROS GOMES, A. P. Sobre a (In)existência de artigo em caboverdiano. Língua portuguesa: ultrapassar fronteiras, juntar culturas 1,p. 1-20, 2010.

MIRANDA, W. O sintagma nominal do caboverdiano: uma investigação semântica. Dissertação de Mestrado. Departamento de Linguística. 
Faculdade de Filosofia, Letras e Ciências Humanas da Universidade de São Paulo, 2013.

MIRANDA, W. O sintagma nominal no caboverdiano. Filologia e Linguística Portuguesa, 15, p. 1-12. 2013a.

QUINT, N. Grammaire de la langue Cap-Verdienne. Paris: L'Harmattan, 2000 .

QUINT, N. O Caboverdiano de bolso. France: Assimil, 2009.

ROBERTS, C. Demonstratives as definite. In: VAN DEEMTER, K.; KIBBLE, R. (Ed.). Information sharing: reference and presupposition in language generation and interpretation. Stanford: CSLI Press, 2002. p. 89-196.

RODRIGUES, U. R. Fonologia do caboverdiano: das variedades insulares à identidade nacional. 2007 - Tese de doutorado em Linguítistica Universidade de Brasília, Brasília, DF, 2007.

STOWELL, T. A. Subjects, specifiers, and X-bar theory. In: BALTIN, M. R.; KROCH, A. S. (Ed.). Alternative conceptions of phrase structure. Chicago: University of Chicago Press, 1989. p. 232-262.

STOWELL, T. A. Determiners in NP and DP. In: LEFFEL, K.; BOUCHARD, D. (Ed.). Views on phrase structure. Kluwer: Dordrecht, 1991. p. 37-56.

SZABOLCSI, A. The noun phrase. The syntatic structure of Hungarian. In: KISS, K. É.; KIEFER, F. (Ed.). Syntax and semantics 27. New York: Academic Press, 1994. p. 179-275.

VEIGA, Manuel. O caboverdiano em 45 lições. Praia: INIC, 2002. 